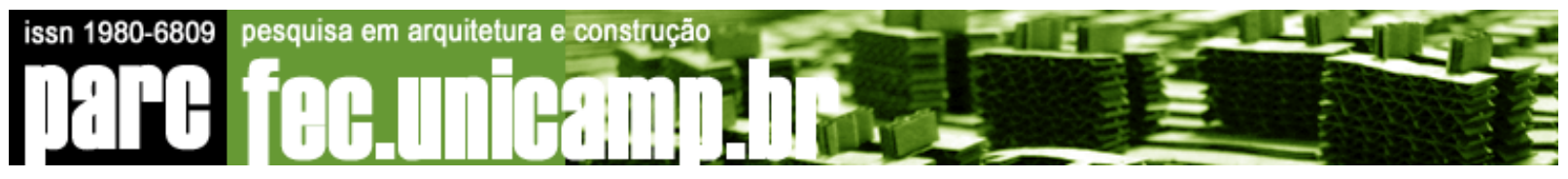

\title{
A Celebração da Utopia Contemporânea do Capitalismo
}

\section{The Celebration of Contemporary Utopia in Capitalism}

\section{RENATA LATUF DE OLIVEIRA SANCHEZ}

Estudante do quinto semestre do Curso de Graduação em Arquitetura e Urbanismo pela Universidade Estadual de Campinas (UNICAMP)

renata_los@hotmail.com

\section{Resumo}

Os anos 1960 e 1970 foram marcados por uma crítica à urbanidade existente através da arquitetura experimental, super focada em tecnologia e computação; já os anos 80 e 90, quando um modelo de cidade contemporâneo se consolidava, deram lugar ao surgimento de uma nova discussão baseada no valor da história e cultura local, com forte apelo nostálgico: o Novo Urbanismo. Pode-se considerar tanto a arquitetura experimental quanto o Novo Urbanismo formas de utopia arquitetônica; no entanto, a última, apesar de não ter muitos exemplos, é uma utopia provável e consolidada, totalmente inserida no capitalismo. E é por isso que consegue progredir dentro de cada cidade idealizada. Proponho neste trabalho estudar a urbanidade criada por Walt Disney e sua Empresa, tanto na questão dos parques temáticos, mas principalmente na cidade de Celebration, FL, USA, dentro do conceito de Novo Urbanismo e também no contexto das "ressemantizações" do pós-modernismo designadas por Manfredo Tafuri. Mostrá-la como um exemplo que, ao contrário de utopias dos anos 60 , baseadas em arquitetura experimental de aspecto tecnológico exacerbado, constitui-se em nova linguagem arquitetônica, ainda que irreal. Ainda, entendê-la como um projeto baseado nos princípios de uma Empresa, e também como reprodução em escala maior de uma ideia do gênio Walt Disney, que pensava na urbanidade de seus parques temáticos a fim de criar locais em que se estabelecessem relações diferentes daquelas das cidades de seu tempo, locais que estimulassem percepções e sensações únicas, afetando inclusive a psicologia de seus visitantes, transformando o que se entende por uma cidade típica do século XX - ideia essa transmitida da Main Street fictícia para uma Main Street real. Pretende-se enfatizar principalmente a relação de Celebration com o sistema capitalista de consumo, relacionado ao discurso de Tafuri, bem como sua validação como cidade.

Palavras-chave: Utopia; Disney; Novo Urbanismo; Pós-Modernidade 


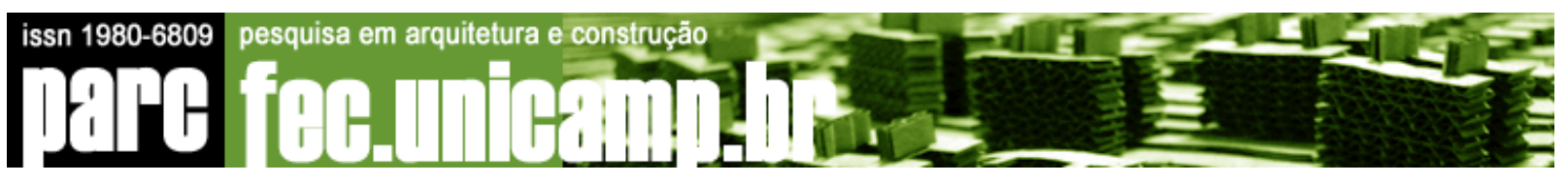

Abstract

While the 60's and the 70's were marked by a critic to the existent urbanity through Experimental Architecture, very focused on technology and computation, the 80's and 90's, a period when a contemporary model of city was being consolidated, gave place to the arise of a new discussion based on the value of history and local culture, with a strong nostalgic approach: the New Urbanism. Both Experimental Architecture and New Urbanism can be considered forms of architectonic utopias; however, the last one, yet having few examples and many critics, is a kind of utopia very likely to be succeeded, as it is totally inserted in the capitalist system. That is the reason why New Urbanism can subsist in each ideal city. I propose in this article to study the urbanity created by Walt Disney and his Company, not only in the theme parks, but mostly, in the city of Celebration, FL, US; inside the concept of New Urbanism and also in the context of the "ressemantization" of post-modernism described by Manfredo Tafuri. It's my intention to show this city as an actual example of - unlike the high technology experimental architecture utopias from the 60's - a new language on architecture, yet unreal (there are few examples like it). Moreover, it should be understood as a project based on the principles of an Enterprise, as much as a larger scaled idea of the genius Walt Disney, who thought the urbanity of his parks in order to create places where other relations could be held, different from the ones established in conventional cities from his time; places that instigated unique perceptions and feelings, affecting even psychologically its visitors, changing the concept of a typical city of the 20th century - an idea that was transported from a fictional Main Street to a real one. I intend to emphasize mainly the relation between Celebration and the capitalist consumption (related to Tafuri's discourse), as well as its legitimacy as a real city.

Keywords: Utopia; Disney; New Urbanism; Pos-Modernity 


\section{A Celebração da Utopia Contemporânea do Capitalismo}

\section{A cidade de Celebration sob a Ótica do Pós Modernismo e da Utopia}

Felicity Scott aponta em sua obra "Architecture or Techno Utopia" para o dossier de Brian Brace Taylor publicado em 1976 na consagrada revista "Architecture d'aujourd'hui", "New York in White and Gray", que discursava sobre a batalha entre os grupos de reação ao modernismo Grays e Whites. Ali aparecia, pela primeira vez, menção ao artigo de Manfredo Tafuri "The Ashes of Jefferson" (SCOTT, 2007, p. 39), o qual colocava um fim em tal batalha. O discurso desses dois grupos, como alternativa a um modelo de arquitetura que chegava ao fim - o modernismo - é base para a discussão do que vem a ser chamado pós-moderno, e constitui-se em fato importante no presente estudo, que visa a entender a relação da arquitetura contemporânea, a urbanidade e o desenvolvimento das cidades pós modernas, bem como a existência de possíveis utopias arquitetônicas e seus efeitos na sociedade; tendo como foco o caso da cidade de Celebration, Florida, US, construída pela Walt Disney Co. A partir da leitura de temas consagrados, com visões mais objetivas sobre a cidade e sua arquitetura, conjuntamente a teorias sobre a pós-modernidade e suas reverberações, a partir de Tafuri, Lefebvre, Hardt, dentre outros mais específicos para a análise do fenômeno Disney, buscou-se analisar Celebration sob diferentes aspectos, não somente sob o julgo aparentemente generalizado de suas fraquezas.

Enquanto nas décadas de 60 e 70 arquitetos renomados buscavam em propostas futuristas e tecnológicas as respostas para solucionar alguns dilemas e entraves da vida moderna nas cidades, na década de 90, a "Charter of the New Urbanism", influenciada por Peter Katzi, explicitava a necessidade de um novo modelo urbano, chamado de Novo Urbanismo. Este, no entanto, era pautado em outros conceitos para uma formação urbana ideal. A relação entre os temas abordados na obra de Scott (e.g. as utopias tecnológicas da década de 60) com a evolução de uma "contraurbanidade" - especialmente a proposta por Katz - em meio ao mundo contemporâneo é um dos objetivos principais deste texto e será desenvolvida ao longo do mesmo através do modelo urbano criado e desenvolvido por Walt Disney e sua empresa, tanto em seus parques temáticos (nos Estados Unidos), quanto, com maior ênfase, na cidade de Celebration, idealizada sob as égides do Novo Urbanismo pela Walt Disney Co.; inserindo-a no discurso de Tafuri a respeito da arquitetura e capitalismo, bem como na questão da busca por uma nova linguagem arquitetônica, frente ao início de uma pós-modernidade. 


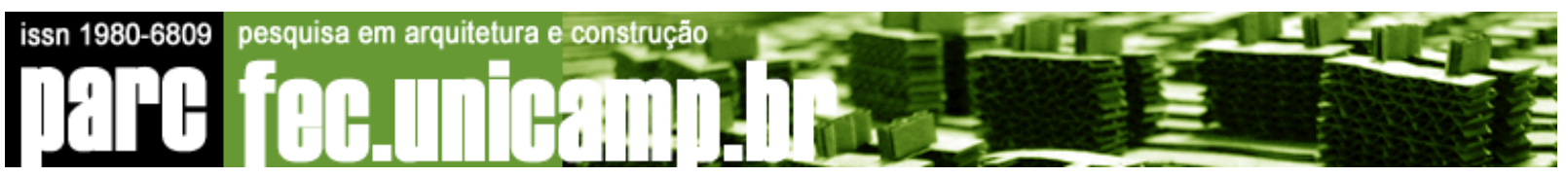

O debate entre os grupos Gray e White, discutido por Brian Brace Taylor em 1976, é fundamental para o entendimento do conceito de "Ressemantização" proposto por Manfredo Tafuri, conceito intrínseco à pós-modernidade, como será visto adiante.

No século XX, movimentos artísticos começam a entender as limitações do funcionalismo, grande cânone da arquitetura moderna. É nesse período que surgem duas fortes reações à arquitetura moderna e suas aspirações em busca de outra linguagem arquitetônica. O grupo denominado "The Whites", formado em 1969, a partir da conferência realizada no MoMA, em NY, que compreendia arquitetos como Peter Eisenman, Michael Graves, John Hedjuk, Charles Gwathmey e Richard Meier, procurava estudar as questões mais básicas da linguagem arquitetônica, questões relacionadas a uma gramática formal. "Quais são os limites, qualitativa e quantitativamente para o léxico de signos arquitetônicos?", “o que faz certa configuração arquitetônica?”, "Quais formas podem ou não ser usadas? E mais importante, como essas formas devem ser articuladas?" (GANDELSONAS, 1978, in: Hays 1998. p. 202) (tradução nossa). Buscavam uma arquitetura que "transcendesse história e cultura; uma arquitetura que é uma força nela mesma, uma linguagem que fala sobre si mesma e que não comunica outras idéias que não suas próprias” (WATSON, 2005) (tradução nossa). Paralelamente a esse grupo, e não exatamente em contraposição, surge a partir do grupo intitulado "Five on Five" o "The Grays", em 1973, com um trabalho publicado na renomada Architectural Forum. Eram parte desse grupo Robert Stern, Jaquelin Robertson, Charles Moore, Giurgola e Alan Greenberg. Sua ideologia é embasada na teoria e prática de Robert Venturi, cuja publicação "Complexity and Contradiction in Architecture”, de 1966, argumentava contra a pureza, simplicidade e clareza do modernismo. Estavam interessados em uma arquitetura mais complexa, histórica e cultural, "baseada na riqueza e ambigüidade da experiência moderna”. Ou seja, Venturi e os Grays consideravam história, contexto, aspectos sociais e culturais em seus projetos, enquanto que Eisenman e os Whites estavam mais preocupados com uma sistematização da linguagem formal da arquitetura.

O entendimento dessas correntes aparentemente opostas é fundamental para uma análise dos modelos arquitetônicos propostos posteriormente, nesses incluído, especialmente, o Novo Urbanismo. Em consonância com essa temática, ressalta-se o contexto econômico vivenciado no final do século XX no mundo, especialmente nos Estados Unidos: o desenvolvimento do capitalismo e a consolidação do imperialismo cultural americano. 


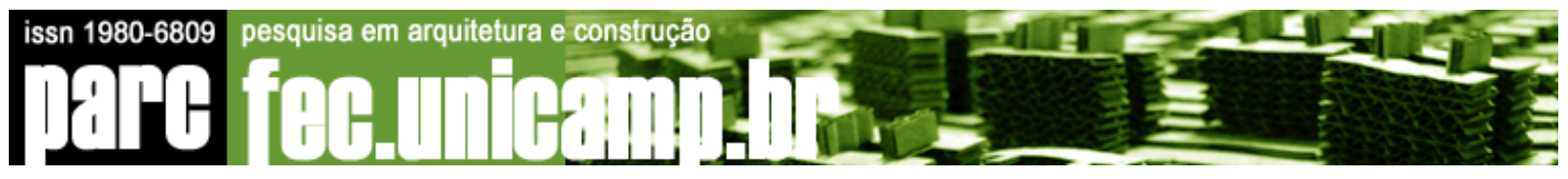

Como menciona Scott, para Bernard Huet, editor-chefe da revista "Architecture d'aujourd'hui", em prefácio da edição de 1976, "a conjunção da crise urbana de Nova York e a concentração da mais altamente refinada avant-garde arquitetônica oportuniza a reflexão sobre o imperialismo cultural americano e a posiciona como um Alerta" (SCOTT, 2007, p. 39). Havia uma relação perfeita e ilusória entre arquitetura moderna e o desenvolvimento econômico e técnico da mais avançada forma de capitalismo. Huet vê a Arquitetura Americana caracterizada por um "consumo arquitetônico generalizado" e a produção arquitetônica baseada em dois sistemas consumidores. O primeiro, baseado no valor de mercado da construção, onde a arquitetura é reduzida a nível simbólico, compreende os trabalhos de Philip Johnson, Kevin Roche e John Portman, com uma arquitetura completamente imersa no sistema de produção. O segundo, que integra a produção arquitetônica no mercado de arte, destinada ao prazer artístico e especulativo do colecionador ou museu, contempla os trabalhos de Eisenman, John Hejduk e Robert Stern, os quais estavam, segundo Huet, condenados a ficarem se fazendo perguntas sobre uma linguagem destituída de qualquer substância (Whites), através da produção de "paper architecture" (aquela cujo conceito de projeto é muito mais importante do que sua manifestação física).

Entretanto, para Huet, os dois sistemas consumidores apresentados não devem ser compreendidos como duas esferas antagônicas ou autônomas; pelo contrário, propõe, assim como Manfredo Tafuri, que nos coloquemos dentro das relações entre o sistema de produção e o prazer individual para que possamos transformá-las, e assim, resolvermos o impasse. Tal posicionamento pode ser realizado para a compreensão de Celebration, criada pelo sistema de produção e mercado, destinada ao prazer e, inevitavelmente, à especulação.

Do mesmo modo, o embate entre Gray e White não deve ser visto como duas facções distintas e totalmente opostas. Tanto para Robert Stern quanto para Tafuri, o debate entre os "Gray" e os "White" deveria ser encarado como um projeto comum de recuperação de uma semântica arquitetônica, agora que o movimento moderno estava perto do fim e um PósModernismo começava a se fixar e ser debatido. De fato, a intenção dos grupos, ao invés de afirmarem suas próprias ideologias e criar pólos antagônicos, era, antes, promover a discussão a respeito da Arquitetura, bem como sobre seu sentido nos tempos atuais. Tafuri afirma que o tema central para os dois grupos era a "ressemantização", que divergia de um grupo para outro apenas nos instrumentos empregados para alcançar seus objetivos. É sobre 
essa "ressemantização", a busca por uma nova linguagem, que se pretende discutir neste trabalho, em correlação com outras abordagens já brevemente mencionadas.

Felicity Scott, em seu livro (2007), questiona como a "ressemantização", central ao debate Gray/White, efetivamente concentrou reavaliações alternativas do modernismo. Aqui, pretende-se questionar se algumas formas de urbanismo surgidas posteriormente de fato podem ser validadas como alternativa ao modernismo; se podem ser consideradas uma linguagem arquitetônica que expressa os ideais contemporâneos e, principalmente, se conseguem por em prática tais ideais, obtendo sucesso frente a um sistema em andamento. Retomando Scott (2007, p. 41), a autora diz que a busca por uma nova linguagem arquitetônica dos Gray/White impedia não só os não mais válidos preceitos de "composição formal, adequação funcional e lógica construtiva" (preceitos tipicamente modernos), mas também as investigações inauguradas por Peter Cook, que ele chamou de "arquitetura experimental", e que deu origem a seu livro, em 1970, com forte repercussão durante aqueles anos.

O debate Gray/White coloca-se, então, contra essa arquitetura, já que esta recusava limites disciplinantes e frequentemente passava por lógicas não semânticas de informação; esse modo de experimentação se abriu a articulações complexas entre tecnologias contemporâneas e ideais sociopolíticos. Era, para Cook, simplesmente experimentar a partir da arquitetura. Segundo ele, neste século, "houve várias ocasiões em que ciência, tecnologia e independência humana coincidiram de um modo que fez a arquitetura 'explodir"' (COOK, 1970, apud SCOTT, 2007, p. 45) (tradução nossa).

A supressão da arquitetura experimental através de um dos pólos do Gray/White foi observada por Richard Pommer, crítico do Artforum, como comenta Scott (2007, p. 45). Em "The New Architectural Supremacists", ele apontou a emergência de Nova York como um contraponto modernista à arquitetura dos anos 60, caracterizada por imagens comerciais, consumistas e de ficção científica. Colin Rowe contrapõe a arquitetura moderna da Europa com a da América: esta última havia, segundo ele, se tornado segura ao capitalismo. Enquanto a arquitetura europeia agiu a partir de uma dialética do esclarecimento, baseada no uso livre da razão e da ciência; a arquitetura americana, o International Style, nasce a partir de um incontestável comercialismo. Tal condição primordial da arquitetura americana não podia ser devidamente atendida pelo experimentalismo inaugurado por Cook, e realizado por arquitetos como Michael Webb, um dos fundadores do Archigram Group, Hans Hollein (autor do ousado projeto para a megaestrutura "Flugzeugträger in der Landschaft" - Portaaviões na 
Paisagem), Friedrich St. Florian ou Arata Isozaki (autor de propostas como "Cachos no Ar"), na medida em que suas propostas extremamente movidas à tecnologia, ficção científica e computação quase nunca correspondiam ao mercado, por serem muitas vezes impraticáveis. Para Eisenman, havia um falso avant-garde nos anos 60. Resta saber então quando existiria o verdadeiro avant-garde, uma verdadeira evolução arquitetônica. Ou, simplesmente, um modelo que correspondesse perfeitamente às necessidades de seu tempo, econômicas e espaciais, e cujas características o fizessem perdurar por outros. Apesar de Eisenman classificar sua obra como parte de um "verdadeiro modernismo" ocorrido nos 1970, talvez haja outros exemplos mais verdadeiros ainda. Se tomarmos por base a influência direta do modelo de consumo para o mundo moderno, e inevitavelmente para a arquitetura, talvez sua "arquitetura de papel" não seja tão verdadeira assim para os tempos em que construía.

Como já mencionado anteriormente, Tafuri declara em "The Ashes of Jefferson" que a Guerra entre os White e os Gray estava acabada. Diz que são sobretudo emblemas de uma condição de trabalho intelectual. De fato, o embate entre Gray e White parece ser no espírito de encorajar a discussão arquitetônica, ao invés de promover os ideais de um ou outro grupo. Tafuri, contudo, não os considera capazes de provocar uma mudança social. Para ele, a agenda pós-revolucionária nos anos 70 mostrou que qualquer tentativa de guiar os movimentos que governam o mundo falharia, pois no capitalismo em que se vivia, o controle é exercido por forças incontroláveis. O homem fica, de repente, em um estado de sonambulismo, inapto a abrir totalmente os olhos, um sujeito sem qualquer poder de ação. $O$ sujeito está submetido às ações automáticas e impulsionadas pelas forças incontroláveis do capitalismo. Ainda, segundo Tafuri,

"qualquer utopia intelectual anticonsumo que procure redirecionar as distorções éticas provocadas pelo mundo tecnológico através de mudanças no sistema de produção e canais de distribuição apenas revela a completa inadequação de suas teorias, em face da atual estrutura do ciclo econômico capitalista" (TAFURI, 1987, apud SCOTT, 2007, p. 48) (tradução nossa).

Ou seja, qualquer tentativa de evitar a inércia onipresente do capitalismo está fadada ao fracasso precoce; isto é, tentar criar uma utopia anticonsumista em um mundo guiado pelos parâmetros de consumo é, no mínimo, incoerente. Talvez seja esse o principal motivo do fracasso de vários modelos arquitetônicos dos anos 60 . 


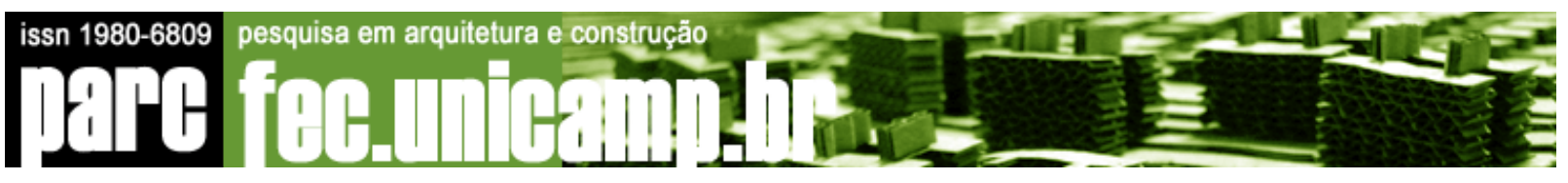

A visão de controle por forças não visíveis também é discutida por Michael Hardt (1996) em "A Sociedade Mundial de Controle", também analisada por Gilles Deleuze. Tal controle característico da pós-modernidade é fortemente presente na utopia de Walt Disney, em sua concepção para seus parques temáticos, bem como para a cidade de Celebration - na verdade, uma reprodução em escala maior de um parque.

Tafuri encara que um dos principais aspectos da "ressemantização" envolve a teoria da comunicação e da mídia. No entanto, argumenta que as relações entre a comunicação e o consumo, intimamente ligadas às inovações tecnológicas e teorias lingüísticas, não foram adequadamente teorizadas pelos arquitetos. A seu ver, as estratégias formuladas em práticas de arquitetura experimental permaneciam inteiramente sem uma eficácia política.

A partir desses pontos apresentados, pode ser estabelecida uma ligação entre: a "ressemantização" proposta no pós-modernismo depois do importante debate Whites/Grays; os modelos utópicos baseados em tecnologia e ficção científica que explodiam nas décadas de 60 e 70; a teoria da comunicação e mídia e a utopia de Walt Disney na construção de seus parques e na cidade de Celebration, FL, US. O debate entre os White e Gray está mais próximo ainda de Celebration do que imaginado: seu plano diretor é de Robert Stern e Jaquelin Robertson, “membros 'Gray'”, além dos equipamentos públicos da cidade - como o town hall - para os quais foram chamados arquitetos como Robert Venturi, Robert Stern e Charles Moore (grupo dos Gray), além de Michael Graves (dos White), Philip Johnson (também envolvido na publicação do grupo "The New York Five" que deu origem ao grupo dos Whites) e Cesar Pelli.

Richard E. Foglesong (2001) apresenta em detalhes a aquisição de terras em Orlando, FL, pela Disney Co., para a abertura de um novo complexo temático, além daquele existente em Anaheim, CA, o primeiro construído, em 1954. Aparentemente - o que pode ser visto como contradição - o próprio consumo, inerente ao capitalismo, acabou por transformar a área dos parques em Anaheim em algo totalmente contra as ideias originais de Walt Disney. Inúmeros hotéis e pousadas, lanchonetes e outros estabelecimentos destituídos de qualquer ligação com o projeto original começavam a se espalhar e preencher as adjacências, algo que o próprio Walt via com maus olhos: "Nós não criamos isso, mas recebemos a culpa" (Disney, Walt. In: FOGLESONG, 2001, p. 59) (tradução nossa). Walt não podia resolver o problema, pois não era proprietário das terras ao redor do parque, nem controlava o governo responsável por elas. Ou seja, incapaz de controlar o mercado e, principalmente, a política na região, apesar de sua incrível influência, Walt Disney estava completamente imerso no 
sistema e em suas limitações. É em Orlando, na Flórida, após inúmeros contratos e discussões privadas com autoridades locais, representantes de condados, responsáveis por planejamento urbano da área, entre outros, que Walt Disney consegue estabelecer, enfim, seu controle absoluto, em algo parecido com um "reino" próprio. A principal aquisição de Disney em Orlando não foram as terras, mas sim, o direito de sua empresa governar exclusivamente toda uma área, sobre a qual seu poder de influência seria total. Para isso, criou-se um distrito, chamado Reedy Creek, englobando suas áreas de domínio e algumas outras, a partir de acordos com condados locais. O principal trunfo para que a política pudesse ter sua eficiência a favor da empresa foi decretar que não poderiam existir moradores permanentes dentro do distrito destinado à criação da "comunidade ideal" (FOGLESONG, 2001, p. 63). Deste modo, com apenas residentes temporários e turistas, estes não exerceriam voto, e assim, os interesses da empresa para o desenvolvimento urbano e econômico da região seriam garantidos. Como mencionado por Larry Whaley, "eles não queriam eleitores controlando o destino da Empresa” (FOGLESONG, 2001, p. 153)

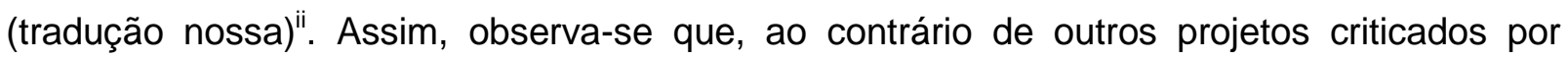
Tafuri, destituídos de uma eficiência política, o caso da área destinada ao complexo Disney em Orlando, e depois, o caso da cidade de Celebration, são extremamente dependentes de uma articulação política, ainda que em moldes não convencionais. Assim como não se queria eleitores na área de circunscrição do complexo Disney, não se desejava eleitores em Celebration: a cidade então pode ser considerada um marco de um "urbanismo corporativo" extremamente fundamentado na lógica do capitalismo e de suas empresas.

O discurso urbanístico de Walt Disney está muito próximo das utopias, supostamente baseado em uma alternativa ao problema encontrado nas cidades de seu tempo: "Não acredito que haja em nenhum lugar no mundo desafio mais importante para as pessoas do que encontrar soluções para resolver os problemas de nossas cidades" iii (DISNEY, 1967, apud FOGLESONG, 2001, p. 67) (tradução nossa). Como solução do problema, Walt acreditava que apenas construindo um modelo totalmente novo, sem precedentes, (princípio da tábula rasa) poderia ser feito um tipo especial de comunidade. Um local em que "as pessoas poderiam viver uma vida que nunca encontrariam em nenhum lugar do mundo" (DISNEY, 1967, apud FOGLESONG, 2001, p. 67) (tradução nossa). De fato, é essa a imagem que se tem dos parques criados por Disney e sua empresa. Locais idílicos, onde as pessoas se sentem bem, imersas em um universo com uma realidade artificial, conduzidas pelos ideais tão bem propagados por uma empresa. Entretanto, não se trata 
necessariamente de uma crítica negativa absoluta. Em tempos em que o urbano se torna caos e solidão em ritmo progressivo, tal realidade artificial pode se constituir em realidade desejável, e positiva. Em termos de composição urbana, o complexo é apontado pelo urbanista James Rouse como "a melhor peça de design urbano nos Estados Unidos"; e, ainda, "Disney elevou o conceito de parque de diversões a um padrão tão alto em sua performance, funcionamento, que se esse se transformou em algo totalmente novo" (1967, apud FOGLESONG, 2001, p. 59) (tradução nossa).

A questão observada na construção do Magic Kingdom em Orlando, em conjunto com todo o complexo ao redor, dotados da mesma linguagem (a de um espaço ideal, controlado) é transmitida anos depois na construção de Celebration (já muito depois da morte de Walt Disney). A construção da cidade se realizou com Peter Rummel, responsável pela Disney Development Co. no final da década de 80 e 90, que executou um plano para os trinta mil acres da Companhia na Flórida, nos condados de Osceola e Orange County (FOGLESONG, 2001, p. 151). A questão agrária envolvendo a empresa é bastante discutida por Foglesong (2001). A Disney Co. possuía onze mil acres livres classificados como propriedade agrícola e, portanto, pagava menos impostos que sobre a área classificada como comercial (onde havia os parques). Em 1989, o responsável pela taxação de propriedades no Condado de Osceola, Bob Day, tem uma importante conversa com o advogado da Disney Co., Rick LaLiberte, a respeito da correta taxação sobre a área livre, que não deveria ser classificada como agrícola, mas sim como comercial, visto que havia intenções por parte da Empresa de construir um centro de compras e uma exclusiva comunidade residencial. Aparte os detalhes da negociação, o fato que culminou na criação de Celebration: a constatação de Peter Rummel de que era possível realizar tudo o que fosse desejável nas áreas delimitadas para fins comerciais, norte da rodovia US 192, e ainda construir para propósitos comerciais e residenciais ao sul da US 192, sem por em perigo a área dos parques temáticos e dos hotéis (e, assim, continuar a pagar menos impostos).

Quando foi anunciada, em 1991, a mídia caracterizou Celebration como a realização de um antigo sonho de Walt Disney, denominado EPCOT (Experimental Prototype Community of Tomorrow), o que foi desmentido por Peter Rummel na época. Porém, quando a cidade saiu do papel, Michael Eisner, CEO da Walt Disney Co. de 1984 a 2005, disse que Celebration havia sido construída, em parte, "para fazer jus ao sonho não realizado de Walt Disney para uma cidade do futuro" (EISNER; SCHWARTZ, 1988, apud FOGLESONG, 2001, p. 151) (tradução nossa) ${ }^{\mathrm{i}}$. 


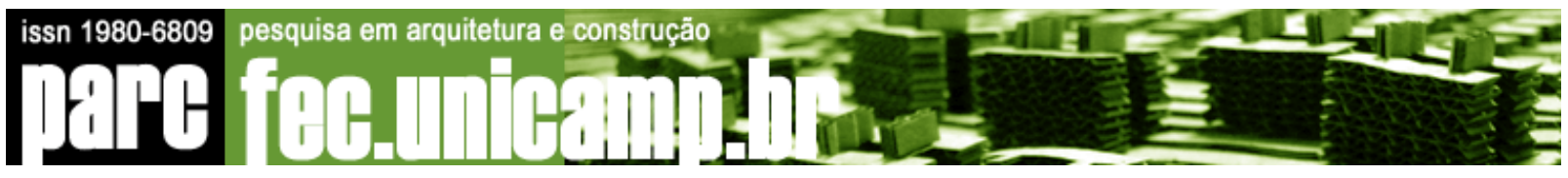

Contudo, o EPCOT realmente construído não corresponde à ideia original de Walt Disney. O projeto, construído no início dos anos 80 , sob o comando do irmão de Walt, Roy, é obviamente influenciado pela geodésica de Buckminster Fuller, com apelo altamente tecnológico. No entanto, o projeto original do EPCOT não era para uma esfera fulleriana; foi pensado como uma sociedade alternativa, englobando também os trabalhadores da Disney World. A ideia de Disney para EPCOT, em 1967, (também presente em toda a sua concepção de urbanidade) era um lugar dedicado à felicidade das pessoas, onde estas iriam viver, trabalhar e se divertir. Tomando como exemplo as novas ideias e tecnologias que emergiam da indústria americana, seria uma comunidade em constante desenvolvimento, sempre testando novos materiais e sistemas. A cidade seria construída em formato radial, contaria com apartamentos altamente adensados ao redor de centros de comércio e negócios; além dessa área haveria um cinturão verde e área destinada à recreação; por fim, além do anel formado pela cidade, ruas residenciais de baixa densidade. Algo que pode ser relacionado à Cidade Jardim, de Ebenezer Howard, e até mesmo à Ville Radieuse, de Le Corbusier. EPCOT foi pensada como uma cidade de vinte mil habitantes, com "playgrounds, igrejas e escolas, bairros distintos e calçadas para as crianças irem à escola" (FOGLESONG, 2001, p. 67) (tradução nossa). Haveria um sistema de transporte multimodal, que levaria os residentes a seu trabalho, nos parques temáticos, e ao parque industrial adjacente. Ao mesmo tempo em que pensava em cada detalhe de sua cidade ideal, Disney pesquisava sobre a criogenia, pretendendo voltar no futuro para ver como seu projeto havia se tornado realidade. Disney morreu e a verba necessária para uma comunidade do porte da imaginada por ele foi considerada inviável por seus sucessores. Uma versão reduzida do EPCOT foi então feita por Roy, irmão de Walt, e seus sucessores, como um dos parques temáticos do complexo Disney World. Daí resultou a construção da geodésica fulleriana e um "falso protótipo de cidade na forma de exibições ao vivo" (MORRIS, 1997) (tradução nossa).

Como relembra Scott (2007), as utopias tecnológicas experimentalistas, caracterizadas por megaestruturas, domos, estavam muito longe de uma tradição arquitetônica, de algo apreensível pela sociedade; eram utopias não executáveis. Na época, parecia que a arquitetura corria um sério risco, tanto quanto o modernismo. O clamor "ordem", existente no "pós-modernismo" e a redemarcação ou reterritorialização defensiva dos limites disciplinantes que trariam à sociedade novamente o reconhecimento de sua arquitetura (SCOTT, 2007, p.3) (tradução nossa), guardam íntima relação com o porquê do sucesso do caso de Celebration. Trata-se de um modelo de cidade facilmente apreensível pelas pessoas, algo que relembra a 
tradição arquitetônica, portanto presente no imaginário das pessoas e no seu desejo de vivenciar essa tradição. Trata-se do oposto do que se pretendia nos anos 60 e 70, e até mesmo o que pretendia Walt Disney em seu projeto de comunidade ideal (EPCOT). Eram ideias que não seriam bem compreendidas pela maioria, modelos urbanos quase impossíveis de serem realizados, ou melhor, de serem bem sucedidos. O EPCOT idealizado por Walt Disney pode ser incluído em uma utopia experimental, tanto quanto as megaestruturas projetadas por Superstudio, Archigram e Buckminster Fuller (o projeto de Walt data da década de 60, ou seja, é contemporâneo às outras ideias). Provavelmente por isso, por seu caráter extremamente ousado e grandioso, e - um motivo decisivo - inviável economicamente, como considerou Roy Disney, o EPCOT de Walt foi "transformado" em Celebration. Pode-se perceber claramente que as duas concepções de cidade quase não guardam semelhanças, a não ser o fato de serem tentativas de uma nova sociedade modelo, de um novo modelo urbano. Apesar do intenso foco em tecnologia aplicado a Celebration, a diferença determinante entre essa e as antigas megaestruturas, é que se trata de uma tecnologia intimamente relacionada a um mercado, e por ser uma utopia consumista, dentro de um sistema baseado no consumo, se torna possível.

A utopia se concretiza em 1995, com a definitiva passagem da Main Street fantasiosa de Disneyland e Magic Kingdom para uma Main Street real: Celebration. Ao contrário do EPCOT de Walt para uma comunidade ideal, com prédios altamente adensados, edifícios de negócios, dentre outras características já mencionadas, Celebration foi projetada a partir dos ideais do Novo Urbanismo, em voga nas décadas de 80 e 90. Combinava um "afiado design urbano com um apelo histórico sensível, que tentava apropriar o melhor do planejamento préSegunda Guerra Mundial” (FOGLESONG, 2001, p. 158) (tradução nossa). Por mais que Peter Rummel se proclamasse não muito partidário de tal concepção urbanística, avaliando os prós e contras, percebeu que a cidade poderia ganhar muito se fosse realizada sob esses parâmetros, especialmente devido ao caráter histórico da corrente. Celebration foi influenciada pelos arquitetos americanos Andres Duany e Elizabeth Plater Zyberk, que projetaram Seaside, FL, uma das seiscentas cidades existentes no mundo baseadas no Novo Urbanismo. O plano-mestre para Celebration, de Robert Stern e Jaquelin Robertson, procurava a analogia com pequenas cidades e vilas americanas do início dos anos 1900, criando assim a atmosfera valorizada tanto pelo modelo urbano proposto quanto pelas postulações dos Gray. 


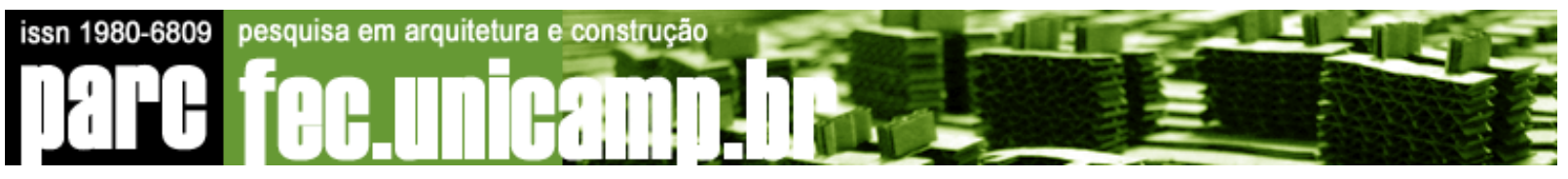

Como exemplar do Novo Urbanismo, a nostalgia, a busca por uma tradição histórica, o senso de comunidade estão fielmente retratados em cada parte de Celebration. Por isso, as casas não podem demonstrar estilos high tech ou, pelo menos, serem construídas de acordo com um estilo contemporâneo. Devem ser projetadas em um dos seis estilos aprovados pela Disney Co.: clássico, vitoriano, revival colonial, costeiro, mediterrâneo e francês. A ideia original abolia os carros das ruas; no entanto, isso não ocorre de fato, sendo o carro atualmente inclusive parte de todo o marketing da cidade, de toda a atmosfera do consumo observada ali - inúmeros carros, de modelos antigos, da década de quarenta e cinquenta, desfilam pelas ruas. Do mesmo modo que em seus parques a cultura do pedestre é fortemente arraigada, a cidade privilegiaria o pedestre e a bicicleta - esta vista inclusive no símbolo da cidade - considerada o meio de transporte ideal.

Para Morris (1997), no entanto, Celebration é uma comunidade do século XIX apenas na fachada, uma cobertura artificial em estilo antigo para uma rede de informações baseadas em "parafernálias da era tecnológica, disposta sobre milhares de cabos enterrados e escondendo suas antenas de telefones celulares". A respeito disso, destacam-se: os hospitais, por exemplo, seriam parte SPA, e as enfermeiras estariam disponíveis através de videophones e computadores. Cada casa seria abastecida por linhas de comunicação dedicadas desenvolvidas pela AT\&T; telefonia, TV a cabo, multimídia digital interativa e serviços de comunicação de dados em alta velocidade, "home security link", controle de energia em casa, serviços de banco interativos, escritório virtual, acesso rápido à Internet de alta velocidade e, o que caracteriza melhor essa comunicação em Celebration: total ligação interativa entre residências, facilidades de saúde, escolas, facilidades comunitárias e estabelecimentos comerciais - possível através de um acordo com a empresa americana de comunicação AT\&T. Além disso, os estudantes poderiam acessar notas de aulas a partir de suas casas, fazer download de tarefas escolares e enviar termos, documentos. O sistema permitiria que os cidadãos "fofocassem por e-mail, pedissem doces de suas casas e até mesmo terem seu sinais vitais monitorados a distância” (MORRIS, 1997) (tradução nossa).

O computador é para Celebration elemento primordial: monitora todas as compras na web, informações traçadas ou web-sites visitados. Aqui estão traços explícitos do controle exercido pela máquina, como um observador constante e sem face. É uma visão do panóptico de Jeremy Bentham modernizada. A super-rede de informação, que chega a todas as casas, pode ser vista também como um "sanitarizador". A rede ajudaria a redefinir instituições da comunidade. Assim como Bentham postulou que sua invenção do panóptico 
poderia ser usada para diversas funções sociais (como hospitais, escolas, alojamentos militares), o computador iria transformar a função social de certos espaços, como a rua, a escola, os hospitais. A rua não mais seria um ponto de encontro ou compras, pois o computador permitiria que quase todas as atividades fossem feitas em casas; as salas de aula se tornariam "cibernéticas", tirando da escola uma de suas funções principais: a socialização. Aqui as críticas começam a se intensificar; lembrando Henri Lefebvre, as necessidades sociais são parte do que as cidades têm de mais interessante a oferecer.

Em "O Direito à Cidade", Lefebvre faz considerações primorosas a respeito do que se deve constituir de fato a vida na cidade. Diz que há para além das necessidades individuais, marcadas pela sociedade de consumo, necessidades sociais e antropológicas.

"As necessidades sociais tem um fundamento antropológico; opostas e complementares, compreendem a necessidade de segurança e a de abertura, a necessidade de certeza e a necessidade de aventura, a de organização do trabalho e a do jogo, as necessidades de previsibilidade e do imprevisto, de unidade e de diferença, de isolamento e de encontro, de trocas e de investimentos, de independência (e mesmo de solidão) e de comunicação, de imediaticidade e de perspectiva a longo prazo. (...) (o ser humano) Tem necessidades de ver, de ouvir, de tocar, de degustar, e a necessidade de reunir essas percepções num 'mundo'. (...) Trata-se da necessidade de uma atividade criadora, de obra (...), necessidades de informação, de simbolismo, de imaginário, de atividades lúdicas. (...) Enfim, a necessidade da cidade e da vida urbana só se exprime livremente nas perspectivas que tentam aqui se isolar e abrir os horizontes. As necessidades urbanas específicas não seriam necessidades de lugares qualificados, lugares de simultaneidade e de encontros, lugares onde a troca não seria tomada pelo valor de troca, pelo comércio e pelo lucro? Não seria também a necessidade de um tempo desses encontros, dessas trocas?" (LEFEBVRE, 1968, pp. 96-97)

Aqui se pode relacionar muito do que Lefebvre diz a respeito da função de uma cidade e do que ela deve proporcionar a seus habitantes ao que acontece tanto nos parques temáticos de Walt Disney quanto na cidade de Celebration. Primeiramente, o tema da previsibilidade, tratado por Alan Bryman (1995, p. 102) a partir das opiniões de autores como S. Waldrep, J. M. Findlay e M.R. Real, a respeito do controle sobre a imaginação, e da passividade dos visitantes em parques temáticos. Esses autores mencionados apontam principalmente para a questão da ausência do estímulo à criatividade do visitante: algo que, especialmente no caso das crianças, que estão na fase de descobrir, inventar, imaginar, supor, criar situações, improvisar, seria importante. A noção de improviso certamente não 
cabe nos parques temáticos; tudo é pré-definido, e há uma lógica para cada atração, e cada caminho percorrido dentro do parque. Esse controle é parte da proposta de Walt Disney para seus "convidados"; segundo Findlay, essa "restrição" à imaginação seria uma estratégia deliberada, já que os visitantes poderiam ser induzidos a se comportar e pensar em maneiras que o próprio Walt Disney quisesse (FINDLAY, 1992, apud BRYMAN, 1995, p. 102). B. Thomas, mencionado por Bryman, aponta para a questão do percurso nos parques:

"Walt queria estabelecer uma continuidade no parque, assim como em um filme; de modo que quando os visitantes passassem de uma cena para a outra, os espaços circundantes complementares não resultassem em um choque [uma mudança brusca], mas que tornassem a experiência toda memorável." (THOMAS, 1976, apud BRYMAN, 1995, p. 103)

Segundo, o fato de toda essa problemática estar ligada ao controle exercido dentro do parque. Assim como a "mão invisível do capitalismo", a que Tafuri comenta ser onipresente, o senso de ordem e controle é muito forte nos parques da Disney - como já discutido anteriormente na questão da própria concepção do complexo urbanístico em Orlando - ainda que isso seja muito pouco percebido por seus visitantes. Um controle que se estende a esferas normalmente inalcançáveis, pois está intimamente relacionado ao psíquico, à mente das pessoas. Para Michael Robert Real, que discute a questão da cultura de massa, trata-se de uma "lavagem cerebral" (REAL, 1977, apud BRYMAN, p. 102) (tradução nossa). Entretanto, convém ressaltar que, como parte da utopia que se pretende exibir no caso Disney, trata-se de uma lavagem cerebral extremamente positiva, a qual o próprio Walt Disney desejava realizar, de maneira sutil, incitando em cada um pensamentos positivos sobre si mesmos, do mesmo modo como foi apresentado na ideia do EPCOT, que deveria ser um lugar no qual as pessoas se sentissem felizes. Se seu desejo era apenas parte vital para a estratégia de controle, é uma questão válida; no entanto, não se pode negar que o poder de influência exercido por essa utopia promove boas sensações. Bryman cita John Hench, antigo vice-presidente de Design em Walt Disney World: "Walt Disney sabia como fazer as pessoas se 'sentirem melhor sobre si mesmas' porque ele podia fazer com que elas acreditassem em si do mesmo modo que ele sentia sobre elas" (FINDLAY, 1992, apud BRYMAN, 1995, p. 102) (tradução nossa). A influência sobre o modo de pensar e as sensações provocadas nos visitantes dos parques temáticos tem grande importância no sucesso do modelo espacial criado; indiretamente, assume-se que essa influência psicológica 


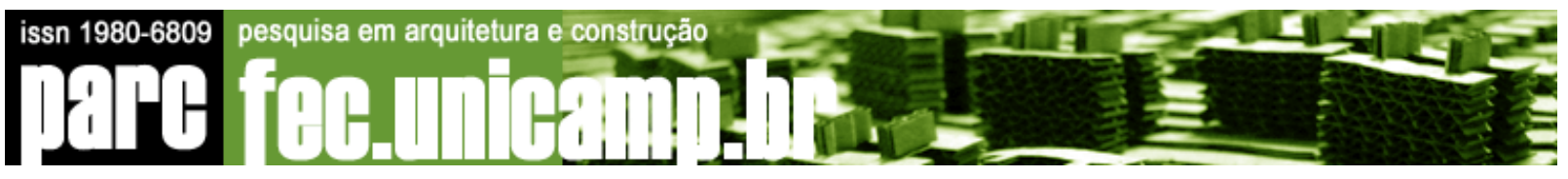

possa garantir também o bom funcionamento de uma urbanidade criada. A utopia aqui nada mais é do que a possibilidade de estar em um espaço que bombardeie emoções positivas, sentimentos de felicidade, prazer e autoconfiança; um espaço baseado no espírito de seus frequentadores; principalmente um espaço em que, ao contrário de qualquer outro local no mundo, não há problemas, não há lembranças ruins. $E$ isso pode ser aplicado em maior escala ao caso de Celebration. Espaços "sanitarizadores", tanto os parques quanto a cidade criada na Flórida ecoam ordem e a ideia de padronização.

Apesar de não haver lugar no mundo mais fantasioso, irreal e, no entanto, adorável, do que o universo criado por Walt Disney em seus parques temáticos, onde certamente alguns tópicos mencionados por Lefebvre como a "necessidade de imaginário, de atividades lúdicas" estão muito presentes, o fechamento em si desse universo limita uma troca mais ampla entre as pessoas, condição que é uma das mais importantes na vida em sociedade, e, portanto, na vida nas cidades. Essa limitação pode ser vista mais claramente em Celebration, pois, sendo de fato uma cidade, não contempla, entretanto, o que deveria ser de mais interessante a respeito: as diferenças, as trocas, os encontros inesperados, o imprevisível, a liberdade de cada um. Em Celebration, a ordem predomina não sob a mão do governo, mas, como já citado, sob a "mão do capitalismo", institucionalizada no regimento pela Disney Co. Não há prefeitos, não há política, não há voto, como já abordado. É uma cidade distinta, baseada em uma empresa, e nas ordens estabelecidas pela mesma. As diferenças devem ser ao máximo minimizadas, e há praticamente um padrão em toda a cidade, seja nos estilos arquitetônicos, seja no meio de transporte, seja na ambientação das ruas, nos tipos de lojas, etc.

Ainda no texto de Lefebvre, "O Direito à Cidade", o autor critica as cidades históricas, que se mantem a partir de um passado. Considera-as apenas como um espaço de exposição, de museu.

"A cidade historicamente formada não vive mais, não é mais apreendida praticamente. Não é mais que um objeto de consumo cultural para os turistas e para o estetismo, ávidos de espetáculos e do pitoresco. (...) a cidade está morta." (LEFEBVRE, 1969, p. 98)

Celebration não é o tipo de cidade sobre o qual o autor escreve. Um modelo recente, quase não tem história. Essa se dá através da reprodução de estilos antigos em suas casas, como o vitoriano, o colonial e o mediterrâneo, por exemplo, em um modelo que relembra as pequenas cidades do século XIX, nas quais a noção de vizinhança era muito presente. 
Celebration tem aproximadamente dez mil habitantes. Construída aproximadamente vinte e cinco anos após a data de "O Direito à Cidade", Celebration pode ser criticada pelo viés apresentado por Lefebvre, o de uma cidade voltada extremamente ao exibicionismo, ao espetáculo, a uma estética que supera qualquer noção de urbanidade ou função citadina. Pode ser considerada, inclusive, um anexo ao complexo temático Walt Disney, já que muitos dos turistas que visitam os parques passam em Celebration para conhece-la. Se a cidade está morta como Lefebvre afirma, isso é relativo. Mais viva do que nunca, a cidade se sustenta por uma aparência criada e investida, por habitantes e visitantes que se entusiasmam com cada parte de Celebration. Seus moradores a adoram e são fieis a ela: antes de comprar uma casa, é preciso assinar um termo de compromisso com o espírito da cidade. Para isso, é preciso estar disposto a renunciar a um modo contemporâneo de cidade, a morar em megalópoles, em meio ao adorável "caos urbano". Mas cabe perguntar, quão viva é uma cidade que desconhece seus limites, na qual não há relações mais sólidas entre seus habitantes? As possibilidades de trocas são, definitivamente, muito menores que em cidades como Nova York, São Paulo. Há, talvez, um por cento das possibilidades existentes nesses centros urbanos. No entanto, são trocas diferentes, em escala diferente, o que qualifica Celebration como um meio urbano tão vivo quanto qualquer outro. Um meio vivo dentro de um sistema próprio, inserido fielmente num sistema capitalista, numa exibição do consumo, numa identidade própria que se mantem constante, não importa o passar do tempo.

Outro ponto importante do texto de Lefebvre, especialmente no que ele afirma por "direito à cidade" é relacionado aos desvios que se deram na busca por esse direito, "a nostalgia, o turismo, o retorno para o coração da cidade tradicional". Afirma inclusive que a reivindicação da natureza (relacionada ao valor da natureza frente ao stress, ao caos urbano vivenciado nas cidades contemporâneas) se anuncia como uma fuga à "cidade deteriorada $e$ não renovada" (LEFEBVRE, 1969, p.108). É exatamente isso que se vê em Celebration: uma alternativa às grandes formações urbanas, um reduto, um refúgio com ar campestre, um retorno a uma tradição passada, a nostalgia pura aplicada, uma cidadezinha pequena em que os pais possam criar seus filhos, sem as influências "malignas" da cidade moderna. Ainda que tal modelo não corresponda ao verdadeiro sentido de cidade, e ao direito a esse sentido.

Para Lefebvre (1969, p. 98), "nem retorno (para a cidade tradicional), nem fuga para frente, para a aglomeração colossal e informe". Ou seja, aplicando ao tema presente, nem a existência do que foi chamado de Novo Urbanismo, nem as propostas futuristas dos anos 60 e 70. De fato, são dois modelos arquitetônicos bastante distantes do que se entende por 


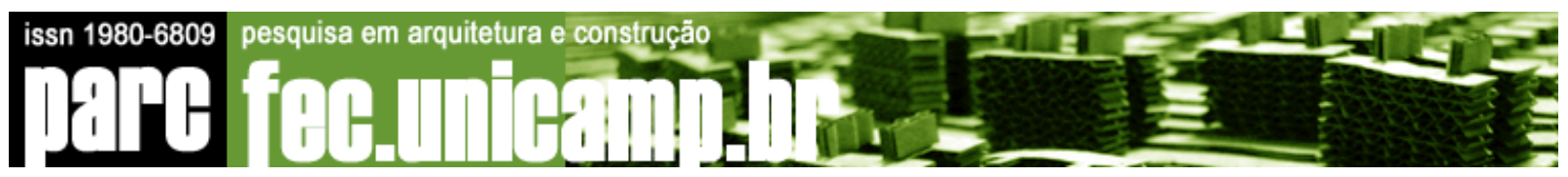

cidade. Ainda que Celebration tenha se consolidado e continue seu desenvolvimento, e que possa ser classificada como tipo de linguagem arquitetônica provável, não é um modelo que possa ser reproduzido em todas as cidades do mundo. Senão, a diversidade estaria fadada ao fim, e a história também, pois só seria considerado um passado digno de memória algo que pertencesse à história de muitos anos anteriores; isto é, a continuidade da história, e de sua relevância para o futuro acabaria sendo estagnada. Resta, portanto, apreciar o modelo criado pela Disney Co. de sociedade ideal, mas analisá-la com cuidado, para que a utopia não seja mal interpretada, para que o espírito coletivo não seja confundido com ideologia imposta. É, sem dúvida, uma cidade que funciona, porém uma cidade que funciona sozinha, e que não permite que nenhum agente estranho ao sistema tente mudar seu funcionamento.

Em conclusão, o que se pretendeu mostrar através do exemplo de Celebration não é que seja um modelo para ser reproduzido em larga escala pelo mundo, muito menos que seja um modelo perfeito, ou que a utopia seja a melhor solução. O que se quis mostrar com a discussão dessa cidade é a sua validade frente um sistema econômico, político e social vigente, validade essa por vezes criticada. Apresentá-la não apenas como réplica aumentada de um parque temático, de uma falsa realidade, mas entendê-la como alternativa a tipos urbanos correntes que acabam, através do consumo desenfreado, sendo por eles próprios consumidos e, muitas vezes, sem o controle tão presente, definhados. Validá-la como cidade pelo bom funcionamento do senso de comunidade, pelo senso de lar. Aqui, a relação casacidade parece mais presente do que nunca. Deve-se celebrar a utopia; a existência de locais como os idealizados por Walt Disney, locais em que a humanidade possa de alguma forma resgatar algumas noções que se perderam na modernidade (não no sentido do estilo), mas que somente dentro dela e a partir das estruturas da contemporaneidade podem ser recuperadas. Afinal, para milhões de visitantes, Disneyland é exatamente como o mundo, só que melhor (SORKIN, 1992).Trata-se, portanto, da coerência clamada por Tafuri, ou interpretando Lefebvre, nem uma tradição, nem um super futurismo, mas um meio. E é neste meio que está Celebration. 


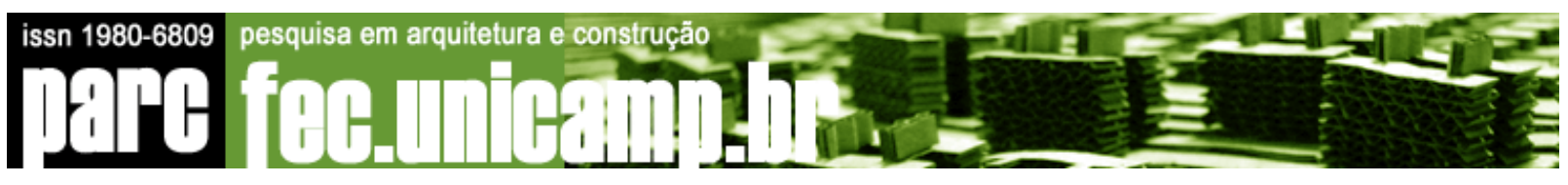

\section{Referências}

BRYMAN, Alan. Disney and his worlds. London; New York: Routledge, 1995.

Congress for the New Urbanism, 1996. Charter of the New Urbanism. Disponível em: <http://www.cnu.org/charter> Acesso em: maio/2011.

COOK, Peter. Experimental Architecture. New York: Universe Books, 1970.

CRAVEN, Jackie. Celebration, Florida. Disponível em: <http://architecture.about.com/od/plannedcities/ss/celebration.htm> Acesso em: maio/2011.

“EPCOT Film”, Walt Disney Productions, 2 fev.1967

GANDELSONAS, Mario. From Structure to Subject. The Formation of an Architectural Language. p.201-223. 1978. Oppositions Reader: Selected Readings From A Journal For Ideas And Criticism In Architecture, 1973-1984. Michael Hays (org). Princeton Architectural Press, 1998. Disponível em: <http://books.google.com.br/books?id=HstEwQiqDgC\&printsec=frontcover\&source=gbs_ge_summary_r\&cad=0\#v=onepage \&q\&f=false> Acesso em: junho/2011.

FOGLESONG, Richard E. Married to the Mouse: Walt Disney World and Orlando. Yale University Press New Haven and London, 2001.

HARDT, Michael. A sociedade mundial de controle. In: Alliez, Éric. Gilles Deleuze: Uma Vida Filosófica. São Paulo: Ed. 34, 2000. Disponível em: <http://www.4shared.com/document/LDPTCalg/Michael_Hardt_-_A_sociedade_mu.html> Acesso em: maio/2011.

LEFEBVRE, Henri. O Direito à Cidade. São Paulo: Documentos LTDA. 1969. p. 96-110 
MORRIS, Mark. American Images of Utopia. Artigo publicado em: Wissenschaftliche Zeitschrift der Bauhaus-Universität Weimar, Heft 3/4. 1997. Disponível em: <http://e-pub.uniweimar.de/volltexte/2008/1286/pdf/mark-morris.pdf> Acesso em: abril/2011.

SCOTT, Felicity D. Architecture or Techno-Utopia: Politics after Modernism. The MIT Press, 2007.

Architecture or Techno-Utopia. In: Grey Room, No. 3 (Spring, 2001), p. 112-126. The MIT Press Stable. Disponível em: <http://www.jstor.org/stable/1262568> Acesso em: abril/2011.

SMOODIN, Eric. (org.) Disney Discourse: Producing the Magic Kingdom. New York; London: Routledge, 1994.

SORKIN, Michael (1992) "See you in Disneyland" in: Readings in Urban Theory / edited by Susan S. Fainstein e Scott Campbell. Blackwell Publishers Ltda, 1996.

TAFURI, Manfredo. Projeto e Utopia. Arquitetura e Desenvolvimento do Capitalismo. Lisboa: Presença. Coleção Dimensões, 1985.

The Ashes of Jefferson. In: The Sphere and the Labyrinth: Avant-Gardes and Architecture from Piranesi to the 1970's. Tradução de Pelligrino d'Acierno e Robert Connolly. Cambridge: MIT Press, 1987.

WATSON, Nadia. The Whites Vs The Grays: Re-Examining The 1970s Avant-Garde. Fabrications: Vol 15, No 1, Julho 2005. Disponível em: <http://espace.library.uq.edu.au/eserv/UQ:135721/n15_1_055_Watson.pdf $\geq$ Acesso em: abril 2011.

\section{Notas}

A Carta do Novo Urbanismo surge após a publicação da obra de Peter Katz "The New Urbanism: Toward an Architecture of Community", em 1994. Em 1993, ele e mais um grupo de arquitetos fundam o Congresso para o Novo Urbanismo (Congress for the New Urbanism). ii "they didn't want voters out there controlling their destiny" (FOGLESONG, p. 153) 


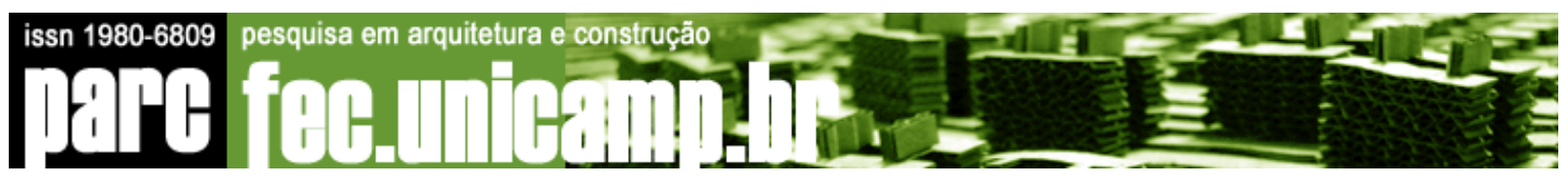

iii "I don't believe there's a challenge anywhere in the world that's more important to people everywhere than finding solutions to the problem of our cities". [Citado por Walt Disney em "EPCOT Film", Walt Disney Productions, 2 fev.1967. apud FOGLESONG, 2001]

151)

"to make good on Walt's unrealized dream for a city of the future" (FOGLESONG, p. 